\title{
HECHOS DIFERENCIALES Y FEDERALISMO COMPETITIVO
}

\author{
JUAN FERNANDO LÓPEZ AGUILAR \\ Catedrático de Derecho Constitucional
}





\title{
HECHOS DIFERENCIALES Y FEDERALISMO COMPETITIVO
}

\author{
POR \\ JUAN FERNANDO LÓPEZ AGUILAR \\ Catedrático de Derecho Constitucional
}

Deseo agradecer, ante todo, la espléndida ocasión que estas Jornadas me brindan para regresar sobre un asunto que me ha ocupado anteriormente; y no por casualidad: es creciente foco de atención para el pensamiento constitucional español. Descuidado largamente por los juristas, el problema de los largamente denominados "hechos diferenciales» en una España a la que reconocemos, casi desde siempre, como un país plural, ha emergido, en realidad, al ranking de prioridades de los constitucionalistas sólo muy recientemente.

Las razones para ello son por descontado variadas, pero no muy difíciles de explicar. En primer término, el cuadro inicial de las preferencias de los contemporáneos estudiosos de la ciencia constitucional en España vino determinado por aquellos objetos más urgidos de tratamiento dogmático y desarrollo normativo; sólo posteriormente ha podido producirse una cierta recuperación de las cuestiones teóricas abiertas a la discusión o a la puesta en conexión del Derecho positivo con otros enfoques - histórico, político y hasta filosófico-convergentes en la comprensión de un problema, no obstante real como pocos. 
Además, por si lo anterior no bastara para explicar muchas cosas, el problema en sí -la revivificación del debate sobre el acomodo o no de los "hechos diferenciales" en el Estado autonómico- ha tardado en presentarse: primero era necesario construir dicho Estado, "hacer" lo que hemos llamado "Estado autonómico sobrevenido" de entre las muchas opciones que la Constitución ofrecía.

En efecto, es sabido que el menú que debía ser afrontado por las Cortes constituyentes (1977-1978) se componía de tres platos, dos de los cuales podían, por así decir, ser digeridos razonablemente casi en la inmediata sobremesa: uno, la legitimación democrática de todo poder político y su sujeción consiguiente a Derecho y a responsabilidad; otro, la aseguración de posiciones subjetivas de las personas $(y$ los grupos en los que éstos se integran) mediante un tupido piélago de garantías jurisdiccionales (y no jurisdiccionales).

El tercer reto, el relativo a la organización de los poderes públicos, y en particular el tocante a la distribución territorial del poder, no podía ser resuelto en esa "unidad de acto".

Aquí, indisputablemente, la carga histórica arrastrada era demasiado densa, y la oportunidad de acertar, de no volver a fallar como otras veces en el pasado, era demasiado buena como para dejarla pasar. Ello exigió al constituyente altas dosis de imaginación. Se pergeñó para ello una combinación de retórica principal (el art. $2 \mathrm{CE}$ ) y constitucionalismo procedimental, merced a la cual fue posible "edificar", no por la CE sino a partir de la CE, un Estado compuesto que ha devenido en la práctica, con incontestable éxito, uno de los Estados más descentralizados del mundo, sin nada que envidiar, en cuanto a intensidad y autenticidad de la reestructuración territorial del poder, a muchos de los Estados que se Ilaman formalmente federales en sus Constituciones.

Durante años, tal reestructuración del Estado —sometido, cual cubo rubick, a los efectos del llamado principio dispositivo, funcionalísimo ingenio por el que determinados actores políticos-territoriales recibían legitimación no sólo para establecer Comunidades Autónomas sino para establecer "suelos competenciales" (no techos, puesto que siempre son $-y$ continúan siendo hoy - revisables al alza) que modificaban, por ello, las competencias del Estado- ocupó lógicamente la atención preferencial de los cultivadores de las disciplinas jurídicas.

Recientemente, sin embargo, el problema de la "diferencialidad" de ciertas CC.AA., su uinsatisfactorio" acomodo en el Estado autonómico $y$, en definitiva, su proyección sobre un esquema de asimetría au- 
tonómica, en el que, conforme a esta fórmula, no todas las CC.AA. disfruten de un estatuto exactamente homogéneo o igual al de las demás en el marco del Estado, ha sido "sacado del armario" y situado como objeto de seminarios, debates y publicaciones crecientes en foros especializados.

¿Qué ha pasado aquí? Varias cosas, pero podemos sintetizar el cambio de situación distinguiendo dos planos de análisis, uno político y otro jurídico.

a) Desde un punto de vista político, se han producido dos fenómenos dignos de consideración. Por un lado, el relativo a las perfectamente conocidas consecuencias de la desaparición de las mayorías absolutas que durante casi 11 años había caracterizado (a beneficio del PSOE) el circuito parlamentario del Estado hasta 1993. La nueva situación de mayorías relativas (primero del PSOE, luego, desde 1996 del PP) requeridas de otros apoyos para llevar adelante un programa de Gobierno (toda vez que las fuerzas principales del sistema de partidos, PP y PSOE, dialogan mal y "a cara de perro", ejecutando consignas fuertemente confrontacionales) se ha traducido, como es obvio, en una multiplicación exponencial del valor de mercado de los votos parlamentarios de las minorías nacionalistas (primero, la vasca y la catalana; luego, y como consecuencia de un efecto-emulación e imitación transparente, la de Coalición Canaria).

Un segundo fenómeno, menos comentado y conocido, me parece sin embargo no menos importante: se trata de las consecuencias de los segundos grandes Acuerdos Autonómicos con los que se ha impulsado el "proceso autonómico": los Acuerdos de 28 de febrero de 1992 (Gobierno, PSOE Y PP) se tradujo expresamente en una "racionalización" y "homogeneización" del Estado autonómico, con la así denominada "equiparación sustantiva" entre las CC.AA. "del 151" y las CC.AA. "del 143 CE" (!?).

Pues bien, hoy cabe afirmar que a partir de esa "equiparación" tendencial se disparó la "fuga hacia adelante» de las CC.AA. del «151", abocadas de algún modo a expresar así su actitud frente a la nueva ronda de "café para todos". Es en ese momento cuando se fleta la imagen del café, sí, pero con leche o doble ración de azúcar o con cruasán o con zumo de naranja... 
Nos tropezamos así, en definitiva, con una encrucijada en la que se recupera nada menos que una aplazada discusión sobre la viabilidad o conveniencia de una reforma constitucional, cuando no sobre propuestas abiertamente inconstitucionales como las de transformar a España en una "confederación" de "soberanías compartidas" con introducción de términos como "secesionismo" o "autodeterminación".

Pues bien, ha de aclararse de inmediato, aun cuando por enésima vez, que nada de eso cabe en nuestro marco constitucional: De un lado la autodeterminación es principio de descolonización acuñado por el Derecho internacional público (Carta Fundacional, de 1945, y Resoluciones de la ONU de 1960 y 1974) para propiciar el acceso a la estatalidad a poblaciones sometidas a una regla extranjera sin titularidad ni disfrute de los más elementales derechos democráticos de participación en el sentido de su destino colectivo. De otro, la secesión en un Estado compuesto, como puso de relieve la histórica Decisión adoptada en agosto de 1998 por el Tribunal Supremo federal del Canadá en el asunto Re: Secession afectante a Quebec, afecta, en cuanto reescritura de un contrato constitucional, a todas las partes de éste y no sólo a la supuestamente afectada de voluntad secesionista, lo que aplicado a nuestro caso implica la previa reforma de nuestra Constitución para abrir paso a un supuesto de secesión convenida y multilateralizada (ha de autorizarla el titular de la soberanía, que es, en nuestro caso, art. 1.2 $\mathrm{CE}$, el pueblo español en su conjunto, y no sólo el vasco, el catalán o el "Gobierno de Madrid").

b) Desde el punto de vista jurídico, por su parte, lo cierto es pura y simplemente que la experiencia autonómica ha puesto de relieve, en el curso de los años, problemas que no podían ser vislumbrados sino después de que se verificaran en la práctica de las cosas. Se trata, a mi juicio, por lo menos de los siguientes:

i. Rendimiento insatisfactorio de las instituciones destinadas a asegurar la participación de las partes en la formación de la voluntad del todo; notablemente, del Senado, sólo nominalmente "cámara de representación territorial", pero también de otras no menos decepcionantes frente a la función que debieran cumplir en el sistema: la Conferencia Sectorial para las relaciones con las CC.Europeas es un ejemplo ilustrativo;

ii. Simultaneidad del proceso de construcción autonómica con la accesión de España a Europa, con lo que las tensiones debidas a la transferencia paralela de competencias a las CC.AA. y de "sobe- 
ranían a la UE no ha hecho sino incrementar el espectro de problemas para los que el actual marco constitucional no ofrece respuestas adecuadas;

iii. Last but not least (de hecho, todo lo contrario, este tercer problema es, para mí, de lejos el más importante de todos), la inadecuación del actual marco jurídico para asegurar los equilibrios económico-financieros básicos de un Estado compuesto de complejidad análoga a los Estados federales: la falta de corresponsabilidad fiscal de las CC.AA., y el consecuente debate sobre los instrumentos jurídicos que debieran servir a ese objetivo, quedan insuperablemente puestos de relieve si observamos la conflictualidad jurisdiccional de la que se ha acompañado a todos y cada uno de los intentos hasta ahora de corregirla o matizarla, tímida o imperfectamente, a través de los Acuerdos de "corresponsabilidad" del CPFF de 1993 (bajo Gobierno del PSOE) y, sucesivamente, de 1996 (bajo Gobierno del PP), todas y cada una de sus traducciones normativas resultaron impugnadas en su día ante el Tribunal Constitucional.

\section{4}

Llegados a este punto, ¿qué hacer ante esta nueva situación? Lo primero, tomarnos en serio el problema y asumir, por qué no, el reto de contribuir desde la óptica inconstitucional a dar seriedad al debate, soporte técnico y acaso instrumentos para su tratamiento, en dependencia de cuáles sean sus términos políticos.

$Y$ lo primero que puede $-\gamma$, a mi juicio, debe- hacer el constitucionalista es afrontar el desafío - hasta hace poco pendiente de tentativa alguna- de construir un concepto jurídico de lo que entendamos por "hecho diferencial constitucionalmente relevante", sólo a partir del cual resulta posible acometer una discusión jurídica sobre la viabilidad entre nosotros de un hecho Estado autonómico asimétrico, esto es, donde no todas las partes tengan constitucionalmente la misma posición frente al todo; y ello no por capricho o vindicación de cada cual, sino por que la Constitución ofrece fundamento bastante, legítimo y razonable para la diferenciación especial en determinados aspectos requeridos, por lo mismo, de bilateralización, con la correlativa asunción de la insuficiencia del multilateralismo para tratar los problemas varios y a menudo complejos - por capilares, $y$, al tiempo, acendrados en la historia- de nuestro Estado autonómico.

Se trataría, en suma, que aun reconociendo el alcance en este marco dinámico de lo que se ha calificado de "emulación» competitiva 
entre CC.AA. - los juegos de "liebres y tortugas" y de "gallina el último»- llegásemos a afirmar qué son constitucionalmente "hechos diferenciales" provistos de ese asiento legítimo y proyección razonable hacia la diferencia, hacia la especialidad y el bilatelarismo, insusceptibles, además, de "exportación" de ningún tipo por más que pueda exasperarse la espiral de los agravios comparativos $y$, paradójicamente, la imitación competitiva, entre CC.AA.

Hechos diferenciales constitucionalmente relevantes -como he intentado argumentar en un ensayo más extenso (Estado autonómico $y$ hechos diferenciales, CEC, Madrid, 1998) - no son cualquier cosa. No son cualquier diferencia o desuniformidad pura y simple entre CC.AA. La desuniformidad y la variedad son lo mínimo que se despacha en un Estado compuesto, el mínimo precio a pagar por los equilibrios y contrapesos territoriales del poder.

Todos los Estados compuestos -incluso los más reputados por su esencial simetría, como es el caso de EE.UU y de Alemania- son variados $y$ heterogéneos si se los mira con el suficiente detalle. Todos los Estados compuestos tienen instituciones peculiares y especialidades en ciertos entes territoriales. El problema no es ese: el problema es qué es lo que tiene asiento en la Constitución que establece, jurídicamente hablando, el poder del todo, no el poder de las partes: la Constitución de la Unión, de la Federación, del Bund, del Estado federal en suma, del Estado global o integrador de las partes.

Pues bien, nuestra Constitución contempla, sí, asiento constitucional para ciertas diferencias jurídicamente relevantes.

No hablamos, pues, en modo alguno, de diferencias materiales (tener costa o no); institucionales (tener Defensor autonómico o no); económicas (mayor o menor nivel de renta); ni siquiera competenciales (tener protección civil, o medios materiales para la Administración de Justicia): Nada de eso justifica en términos constitucionales una alegación sostenible de "hecho diferencial». Equivale, antes bien, a una banalización y disolución por tanto del hecho diferencial constitucionalmente relevante.

$Y$ éste es, sencillamente, el que cumple tres requisitos: a) Relevancia juridica; b) Asiento constitucional razonablemente inferible de la Constitución; c) "Blindaje» de su fuerza pasiva frente a modificaciones unilaterales, sean provenientes del Estado, sea de la Comunidad Autó- 
noma, y desde luego de cualquiera que no cuente con el apoyo expreso de los representantes de los destinatarios o sujetos jurídicos de la "diferencialidad».

Con esos requisitos en mente, no es "hecho diferencial» el hecho minero de Asturias ni el "hortofrutícola" murciano; ni el inframunicipal castellano-leonés ni el uniprovincial riojano. Es hecho diferencial el inferible, a mi juicio, de las siguientes determinaciones constitucionales:

a) Lengua cooficial (art. $3 \mathrm{CE}$ ) y su proyección sobre la cultura, las instituciones, los procedimientos administrativos y jurisdiccionales;

b) El acervo histórico-institucional de naturaleza total: Disp. Ad. $1 \mathrm{y}$, a ciertos efectos, el Derecho civil total o especial (art. 149.1.8 CE), también proyectado éste sobre especialidades en la organización jurisdiccional de las CC.AA. que lo posean.

c) El «hecho insular» (138.1 CE) va aportar también algunas especialidades normoinstitucionales esencialmente "inexportables", caracterizado como está por la interposición de un escalón intermedio (el escalón insular, encarnado en la persona jurídico-pública Isla y su órgano de gobierno y representación, el Cabildo (nsular), con legitimación directamente democrática en el caso canario - a diferencia del balear, donde esta legitimación es indirecta-.

d) La especialidad económico-fiscal directamente inferible del Concierto Vasco, del Convenio con Navarra (Disp. Ad. 1) y del Régimen Económico y Fiscal canario (Disp. Ad. $3 \mathrm{CE}$ ).

Nos hallamos, en efecto, en todos estos casos, ante situaciones especiales de las que, por expreso designio de la Constitución, resultan "alcanzadas" sólo ciertas CC.AA.; no así otras, por más que se empeñen y se pongan como se pongan.

Cierto, por supuesto, que la Constitución no "construye" por completo la entidad, el montante o la proyección de dichas diferencialidades. Pero también que las mismas resultan razonablemente inferibles de la misma, y completadas después en el llamado "bloque de la constitucionalidad". 
Además, estas diferencialidades, y esto importa subrayarlo, no se condensan tan sólo - ni siquiera, en ocasiones, preferentementeen el plano competencial. Una vez más, la identificación mecánica entre la problematicidad del Estado de las autonomías y su dimensión competencial es, más que un mal (en cuanto que difunción), un error, del que derivan otros muchos y que conviene, por tanto, combatir con energía en todos los frentes relevantes.

En efecto, muchos de los equívocos que empecen este esfuerzo tienen un origen común. Aunque, una vez más, de todo esto me he ocupado extensamente otras veces, me permitiré mencionar aquí sólo algunos de acuerdo con lo ilustrativo de su especial importancia:

a) El equívoco de la "historicidad». No hay CC.AA. más históricas que otras. Y la historia, por demás no es patente de corso permanentemente activa ni tiene repercusiones constitucionales permanentes. Si acaso, indirectamente, es exención procedimental (Disp.Trans.2 CE). Pero no irradia mejor título que el racional-democrático. La experiencia registrada por la Comunidad Autónoma de Andalucía lo demuestra. Además, todo el mundo tiene una historia que echarse a la espalda, y ésta por lo demás es susceptible de infinitas reinvenciones.

b) El segundo equívoco de los "dos grupos de CC.AA.": "dos grados" o "dos velocidades"; dos categorías, en suma, de dignidad autonómica. Pero a pesar de la fuerza que adquiere el valor de cambio de esta moneda en circulación, la moneda sigue siendo falsa: There's no such thing. Es falsa la percepción de "dos bloques" de CC.AA.: de entrada, siquiera sea porque las vías utilizadas para el acceso efectivo a la condición autonomía, como los caminos del Señor, "fueron casi infinitos y aun más inescrutables", como ha expresado Pérez Royo. No hubo, en otras palabras, ninguna CA que se atuviese con escrúpulo al rigor procedimental del art. $151 \mathrm{CE}$ (Andalucía fue la única que en realidad lo intentó, pero, fracasado el referéndum de ratificación de la iniciativa en la provincia de Almería, necesitó alguna "ayudita" de constitucionalidad no dudosa sino simplemente improbable). En cuanto a las CC.AA. "del 143 CE", quepa decir sencillamente que fueron muchas de ellas las que procedieron "con truco". Pero es que, además de esto, no puede perderse de vista que los efectos de la opción procedimental no son tampoco permanentes. Lo hemos adverado mil veces: Todas las cotas competenciales son revisables al alza (hablemos por ello de "suelos", no "techos competenciales")... y las arquitecturas institucio- 
nales son modificables también, para hacerse más complejas y completas, más "paraestatales" en suma, a gusto del consumidor.

No hay pues, desde el rigor técnico del dato constitucional, "grupos de CC.AA.". Y es constitucionalmente ilegítimo predicar, por eso mismo, una impronta permanente a partir sólo de la vía procedimental accionada de conformidad al relativo principio dispositivo:

Dicho sea con otros términos, no cabe protesta legítima, pues, frente al café para todos; al menos no ninguna otra que no quiera apostar por su construcción jurídica.

Llegamos aquí al punto central de nuestra argumentación. Al meollo que refleja que la dificultad de construir, partiendo del dato constitucional $-y$ ello sea sin perjuicio, insistimos, de la importancia que en otros órdenes de la vida y en otros planos de análisis, otorgamos a los datos de la historia (la cuestión regional, que siempre ha estado y está ahí), de la política (la búsqueda del mayor consenso), o de la sociología (en la identificación socialmente percibido, muy fuerte en la transición, entre la democracia y el autogobierno o devolution de poder desde el Estado a las regiones), toda conceptualización jurídica del hecho diferencial que pueda ser un instrumento útil para el debate hacia su conducción o adecuado tratamiento, radica precisamente en la perseverancia de múltiples resistencias a hacer del dato jurídico el único instrumento cierto para su identificación y para su manejo.

El ejemplo canario, como he sostenido en otro lugar, es en este sentido paradigmático.

Jurídica, no histórica ni foral, es, en efecto, la construcción del hecho diferencial canario. Así, efectivamente, esta diferencialidad aparece, prima facie, fundada en una determinación directamente constitucional: concretamente, en la Disp.Ad.3 CE, revestida luego de posterior concreción, desarrollo y completamiento en el Estatuto de Autonomía canario (LO 10/82: piénsese en sus especialidades en la forma de gobierno; en el nivel insular de gobierno directamente democrático en los Cabildos insulares y sobre todo en el Régimen Económico y Fiscal canario, con sus diferenciadas vertientes material y formal), y en las leyes estatales 20/91 y 19/94 del Régimen Económico y Fiscal, así como, decisivamente, blindado en el Derecho primario de la "Constitución" europea (art. 299 del TUE según fue reformado en Amsterdam).

c) Y aún un tercer equívoco: el que concentra el debate en el frente competencial. Ni la historia ni el carácter "nacional" se proyectan necesaria ni principalmente en el plano competencial, ni la histori- 
cidad ni la nacionalidad son desde luego franquicia para una mejor condición de suelo competencial: cubiertos los ciclos temporales (5 años) marcados por los arts. 147.3 y $148.2 \mathrm{CE}$, todas las CC.AA. se encuentran legítima y democráticamente "destopadas" por la voluntad democrática de sus ciudadanos (sujetos/ destinatarios/ electores).

En definitiva, ninguno de esos datos por definición constitucional revisables pueden prestar asiento para la vindicación de un "hecho diferencial constitucionalmente relevante".

Por contra, a mi juicio, tal hecho diferencial tiene que venir arropado en los siguientes parámetros objetivos:

i. Poseer relevancia jurídica (no es un hecho exclusivamente material, ni una situación social o económica como la "deuda histórica" andaluza, ni siquiera tampoco una situación política, por permanente o estabilizado que parezca: un partido nacionalista con opciones de gobierno autonómico o en disposición de influir en la política estatal: aunque a menudo lo parezca o se identifique con ello, constitucionalmente hablando el hecho diferencial "no es esto" no es esto);

ii. Disfrutar de asiento directo o razonablemente inferible de la CE (aun cuando desarrollado y concretado en EE.AA. y normas complementarias, como las leyes del Concierto Vasco o del Convenio $\mathrm{Na}$ varro, o las leyes estatales del REF canario, o incluso por su proyección en el derecho europeo de la "ultraperificidad" canaria); y

iii. Hallarse blindado frente a un cambio que no venga promovido o "autorizado" por los sujetos jurídicos de la diferencialidad (lo que excluye, por cierto, a Ceuta y Melilla, susceptible de desprotección por el legislador orgánico estatal: «el Señor me lo dio, el Señor me lo quitón, sin perjuicio de las importantísimas asimetrías que en varios planos de análisis, procedimiento de acceso, institucional y sistema de fuentes y aplicación del Derecho del Estado, importa la singularísima incardinación de Ceuta y Melilla en el conjunto del Estado autonómico, merced a las LL.OO. 1 y 2/95; leyes estatales, con todo).

Caminando ahora a alguna suerte de conclusión y propuesta de Derecho prospectivo: nuestra Constitución de 1978 puede ver completado su éxito sin precedentes en toda la historia anterior de nuestro constitucionalismo. El constituyente puede asegurar, por tanto, una satisfactoria "digestión" del tercer plato del menú. 
Pero para conseguir ese éxito, con el que con el instrumento del Derecho (y por supuesto el ejercicio legítimo de la acción política) hemos conseguido obrar el milagro de la composición territorial del poder contra el que en el pasado se estrellaron no ya con estréptito sino con sangre y extrema violencia experimentos anteriores a todo lo largo y ancho de nuestras eras moderna y contemporánea (toda vez que la "cuestión regional" no nace en las Guerras Carlistas; pregúntese, si no, a la historia por las repercusiones en España de la Paz de Westfalia de 1648 o del Tratado de Utrecht de 1713), para conseguir eso, decimos, es preciso y legitimo un mayor nivel de compromiso del constitucionalismo democrático con el problema.

En otras palabras, procede discutir abiertamente la viabilidad de una reforma constitucional que de nuevo tratamiento a las cuestiones en que su texto originariamente pactado se ha quedado obsoleto. Tiene nada menos que 20 años. Cada generación, al menos, tiene derecho a plantearle las modificaciones oportunas. Pero sin perder de vista que se trata, todavía, de "construir» España, no de "deconstruirla".

Quiere con ello expresarse que sigue siendo imprescindible pensar España como categoria constitucional. Una unidad constitucional no de "destino en lo universal", sino de disfrute de un espacio común de libertades $y$ derechos garantizados equitativamente, con mandato de solidaridad y redistribución de riqueza y con prohibición de discriminaciones (art. 1.1, 2, 9.2, 14, 23, 24, 31, 138, 139, 149.1.1, 157 y 158 $\mathrm{CE}$, entre otros).

Ahora bien, hay más problemas.

España peca ya -lleva tiempo pecando con largura, sin duda como consecuencia de una "sobrerreacción" más a lo anterior, la experiencia del franquismo y la difícil transición- de un exceso de «conservadurismo constitucional'». Y procede, sin más, empezar a superarlo ya, cuanto antes mejor, aunque no podemos ignorar las potentes $V$ buenas razones que lo explican.

Al lado de las habitualmente colacionadas (riesgos a evitar, la teoría de la "caja de pandora" o del "melón constitucional", la escasa raigambre democrática de los españoles y su tendencia a desandar lo trabajosamente andado), lo cierto es que otras razones no menos importantes explican la situación actual, propendente, en síntesis, a una "italianización" del debate sobre la reforma de la $C E$, en el sentido de 
convertir ese debate en un espantajo retórico de carácter cada vez más virtual e inefectivo, en el que todo el mundo habla de ello y finge trabajar en ello (»hace como que se plantea la reforma"...) pero nadie la desea y la hace viable en realidad.

De un primer lado, el PP disfruta de una situación privilegiada para su sorpresa: después de haberle prestado un apoyo sólo tibio, parcial y reluctante (y no sólo los " 7 magníficos" ex ministros de Franco que acompañaron a Fraga en su viaje desde la derecha post-franquista), los herederos de AP se ven ahora erigidos en defensores objetivos del continuismo constitucional frente a las desconcertantes propuestas provenientes de otros ámbitos del espectro político.

De otro segundo lado, el PSOE tropieza con obstáculos de orden psicobiográfico para poder abrirle paso con cierta energía y sinceridad a una eventual reforma de la Constitución: la misma generación de líderes que hizo la transición y se comprometió con una Norma que es, en buena medida, la gran obra de sus vidas, continua en primera línea, renuente a la renovación interna o generacional como en ninguna otra fuerza del arco parlamentario. En el "conservadurismo" de la Constitución le va a esa generación su propia supervivencia política. No dejarán suceder, por tanto, previsiblemente, reformas de ningún calado. Su propensión será, antes bien, a «italianizar» el discurso.

No menos italianizante es, en tercer lugar, la actitud siempre ambigua - por no emplear otros términos más expresivos- que ha caracterizado siempre el juego de los nacionalistas: proclaman su insatisfacción o reticencias varias frente al texto constitucional, pero lo cierto es que no apostarían nunca seriamente por cambiarlo, toda vez que han sido los que más provecho han obtenido, continuada e invariablemente, de un statu quo constitucional caracterizado como ningún otro por los rasgos de permanente "apertura", "incomplitud", "disposición al cambio"... merced a la permanente vigencia y proyección del principio dispositivo en los planos institucional, competencial y financiero.

¿Por qué iban a querer cambiarlo? ¡Les ha ido de miedo con éste! ¡Sólo tendrían que perder de un "rearrangement" dirigido a clarificar de algún modo las reglas del juego en que encuadrar las actuaciones del Estado y las CC.AA.

Las actuales incertezas constitucionales son, en otras palabras, un ideal y apetecible activo constitucional para los nacionalistas. Ningún cartesianismo normativo, ningún "cierre" del "Estado persistentemente abierto" siquiera por la vía ofrecida por el virtual «sumidero 
competencial» que en la bañera del Estado supone el art. 150.2 CE.... ningún cierre va a prestarle ningún favor a los hasta la fecha prósperos proyectos políticos de los nacionalismos periféricos.

¿Dónde quedarian entonces las "liebres $y$ tortugas", agravios comparativos, emulación competitiva, juegos de "gallina el último", la anorexia fiscal y la bulimia competencial, objetiva - no subjetiva, insistimos - fundada en un status quo abocado a producir esos efectos y alimentarlos con variado tipo de incentivos y estímulos objetivos.

La mejor - si no, en rigor, la única- solución, al menos una solución que sea digna de confianza, puede provenir honestamente de una reforma constitucional prospectiva ... e inviable.

Lo primero, por supuesto, aprovechar para eliminar todo lo que de inconfesadamente transitorio hay en el Título VIII de la CE (que es, a poco que se lo examine, una verdadera enormidad).

Readecuar el marco normativo al itinerario ya cubierto y a las nuevas necesidades planteadas en el camino. Reformar el Senado como cauce de participación de las partes en el todo; abrir la UE a las CC.AA., retocar quizá la posición de las corporaciones locales y su autonomía local; reordenar los equilibrios económico-financieros del sistema (abrir la corresponsabilidad de las CC.AA.) ... son los desafíos a "atacar" de esa nueva llamada a la mesa constituyente (metáfora ésta, por cierto, nada inoportuna a la luz de lo mucho que se blasona de cuánto de la Constitución se coció, hace más de 20 años, en opíparas y largas cenas en restaurantes de Madrid y otros cenáculos).

La "magia» debe consistir pura y sencillamente en desnudar a la CE no sólo de Derecho transitorio sino también, más importante, de todo lo que sea constitucionalismo de las partes y no constitucionalismo del todo. Esa es nuestra diferencia, y no el quantum de descentralización, con la Constitución de los EE.UU. de 1787 o con la GrundGesetz de Bonn de 1949.

Dicho sea con claridad: no hay ninguna otra Constitución en el entorno habitual de la comparación en la que sean registrables niveles de presión análogos, de manera sostenida, sobre la Constitución del todo como presupuesto jurídico y garantía de su unidad; precisamente porque lo que aquí está en discusión no es el poder del todo (por lo demás, siempre expansivo, tal y como evidencia el federalismo compa- 
rado)... sino el poder de las partes en conflicto, en pugna competitiva o en detrimento del todo, que es lo que ha caracterizado $-y$ repetimos, ello es dato de la realidad objetiva, no derivación subjetiva o actitudinal- la dimensión abierta de nuestro proceso autonómico fundado en el principio dispositivo.

Esta red de elementos interrelacionados explica en buena medida que se haya desdibujado entre nosotros la elemental dimensión de la Constitución no sólo y exclusivamente como Norma suprema, fundamental, y superior de nuestro Ordenamiento -idea que, por rompedora con nuestras antecedencias, necesitaba ciertamente ser subrayada con énfasis- sino como resultante de un gran pacto político (covenant, arrangement, deal, compromise...) para la integración de una comunidad política históricamente formada desde el pluralismo político y la diversidad territorial.

Es ahí donde, quizá, se halla la diferencia crucial de nuestro proceso con respecto a otras experiencias de distribución territorial del poder; la clave de nuestros activos y pasivos, nuestra gloria y miseria. Eso es lo que, a la luz de 20 años transcurridos y tantas metas alcanzadas, conviene acometer ahora.

Sustituir, en suma, los mimbres de una situación de emulación competitiva, nacionalismos desagregadores o centrífugos $-\mathrm{v}$, a veces, cómo no, una y otra mezcladas con oportunismo político- por los de un Constitucionalismo integrador para un Estado compuesto, plural, plurinacional, plurilingüístico y pluricultural. Compatible e integrador de diferencialidades y bilatelarismos completivos, si no correctivo o moduladores, de la unidad esencial y del multilatelarismo participativo que deben caracterizar, en su original diseño, a nuestro Estado autonómico.

$Y$ todo ello consignado y protegido y garantizado por una Constitución funcionalmente federal, la Constitución del todo, de la unidad esencial del Ordenamiento/ sistema y la igualdad entre españoles.

Un salto en definitiva hacia un sistema federal menos inconfeso y disfuncional, más maduro y responsable, más solidario $y$ diferencialista, más asimétrico y en esa misma medida más respetuoso con la necesidad igualitario de tratar desigualmente a los desiguales e igualmente a los iguales. 
La síntesis, como se ha apuntado en la doctrina, es Estado federal y hechos diferenciales solidarios, no competitivos ni desagregadores ni centrífugos. No "deconstrucción de España", que sigue siendo necesaria para garantizar la redistribución de riqueza y renta interpersonal e interterritorial. Porque, después de todo, ¿Qué otra cosa, si no, es un Estado a estas alturas?

Pero, como decía, dudo mucho que nada de eso vaya a activarse mañana, ni pasado mañana.

Muchas gracias, pese a todo, por esta oportunidad de participar en un debate oportuno y necesario. Las intervenciones, ponencias y comunicaciones efectuadas por los participantes a estas excelentes Jornadas de estudio y reflexión sobre esta problemática lo testimonian, esto pienso, con expresiva holgura.

Tarde o temprano cundirá. 